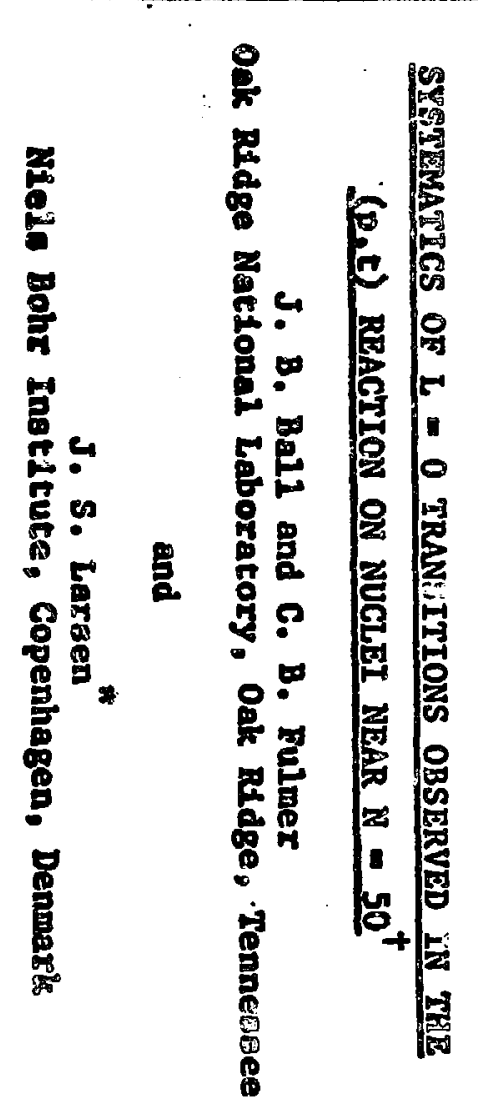

8
3
3

eे

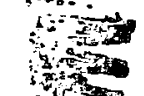

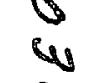


higher energles and are generally of considerabit strength. They axe excited In the $(p, t)$ reaction by removal of a neutron pair fron the clesed core.

In this paper we show results from some of our recent $(p, t)$ studies on nuclet near $N=50$. For this report, we w1ll discuss only the L - 0 Rrangitions observed in zeactions leading to or from nuclet wh $\mathbb{N}$ - 50 .

\section{EXPERTMENTAL METHOD}

Energy spectra were taken at $5^{\circ}$ intervale cver an angular range froso '5 to 45 degries. The tritions were detected with nuclear emulgions in the ORIC broad-range optstrograph facility. Incldent protion energies used were varied from 31 to $40 . \mathrm{MeV}$ depending upon the apecific experimental requirementa and oversil experimental resolution was about $20 \mathrm{keV}$.

\section{RESUETS AND DISCUSSION}

The $\mathrm{i}-.0$ transitions observed in the $90 \mathrm{zr}(\mathrm{p}, t)$ and $92 \mathrm{zr}(\mathrm{p}, t)$ reactions are sumarized in Fig. 1. The intenglties indicated for each transition are obtalned by watching the angular distributions at the first maximum. These numbers thus reflect only ith = relative cross sections measured and are uncorrected for effects of reaction dynanics and configuration changes. Only the ground atate cransition 10 shown for the $90 \mathrm{zr}(p, t)$ reaction since thic represents the bulk of the $\mathrm{L}-\mathrm{O}$ exanaltisin atrength for pickup from the - 50 core.

The level at $1.76 \mathrm{keV}$ in $90 \mathrm{zr}$ is generally attributed to the proton excitation discuses d in the Introduction... This type of state has been observed with the $(p, t)$ reaction on all of the efrconiun isotopes and the obeerved ot:rengthe thown to be conststent with such an interpietation. ${ }^{1}$

The trevioltion strength to the three higher levels lo attributed to rewovel of neutron patre from the $\mathrm{H}$ - 50 core. Thase Iovelo thus reprecent 
the "palring-v1bration" strength observed in th1s nucleus. There are oeverel Interesting points to note about these levels: 1) The totel intensity sums to only about $2 / 3$ of that for the ${ }^{90} \mathrm{zr}(\mathrm{p}, t)$ ground state transition. 2) Although the most intense level is found at the same reaction Q-value as the ${ }^{90} \mathrm{Zr}(\mathrm{p}, t)$ ground state transtition, the center-of-gravity of the trangltion otrength 18 of less regatiwe Q-value with apprectabie intensity to the $4.13 \mathrm{HeV}$ level. 3) There 18 diacinct oeparaston between the low lying "valence" $0^{+}$levele and the levelo carrying the pairdng-vibration otzength.

These zirconium data are from some of our earliest work in this regicn and the principal result was to show that, for these nuclel, wajor deviations aze found from the predictions of the aimple harmonic form of the pairingvibration model. ${ }^{2}$ Recently, Sprensen has ohown that by Including the effecte of particle-hole correlations the olsserved energy shifts, lose of intenotty. and fractionation of pairing otrength in $30 \mathrm{zr}$ can be well accounted for within the framework of the pairing-vibrational model. 3

We have extended the $(p, t)$ atudies to Include No $_{0}$ and Ru 180topes. The $L$ - 0 transitions observed in the $92 \mathrm{Wo}(p, t)$ and $94 \mathrm{~W}(p, t)$ reactions are sumarized In Fig. 2. Part of the wativation for this work was to locate the level coxresponding to the excttied $\mathrm{O}^{+}$expected from the proton configuration. The level observed at $2.52 \mathrm{kaV}$ is our candidate for such a description ofnce 14 agrees well with the excitation energy predicted by atmple shell-wodel salculations fos the $N=50$ nuclet.

The patcer of of the patring vibration otrength in 92 wo is changed eignificantly fron $90 \mathrm{zx}$. Although there to a $\mathrm{O}^{+}$level observed near the oneres expected for the patring vibration (In the haxwonic form of tho made1). It carries alwopt none of the expected strangth. Instead, the mafor 
transition Intensity 10 observed to a level over I MeV less bound. In addition, the observed $0^{+}$levels are rother evenly opaced wth the orchorgonel proton state being oomewhat closer to the pairing vibration than to the 8round state. The pattern observed here closely resembles that observed previously for the neodymium 180topes at $N=82.4$

The I - 0 transitions observed in the ${ }^{96} \mathrm{Ru}(\mathrm{p}, t)$ reaction are ohown in F1g. 3. In this case the $(p, t)$ reaction on $N$ - 50 cannot be gtutiled since ${ }^{94} \mathrm{Ru}$ to not stable. Of the levels observed in ${ }^{94} \mathrm{Ru}$, the begt candidate for the excited proton $\mathrm{O}^{+}$appears to be the level at $2.99 \mathrm{KeV}$.

SAnce the mase of ${ }^{92}$ Ru 18 uniknown, we cannot deterinine the cuergy shift of the patring vibxation otrength. He do observe, however, that the exatted $0^{+}$levelo have now becone rather tightly grouped.

The Interattles ahom in the ftgures hove been normalized in each case to the respective $\mathrm{H}$ - 52 to 50 ground eitate trangitions since, the airconfu data was not originally obtatned at 31 Viev. These reactone heve been reatudied at $31 \mathrm{MeV}$ to allow a clearer Intercomparioon between the three ceries. These resulte are not yet complete, but it meens clear that we observe a defintte trend of decreasing ctrength fron removal of neutron pairs from the $n=50$ core as the 2 of the inotopas in increased. A final andyets sade by extracting eninancoment factore from comparioon wh th DWB calculatione Io In progrees.

\section{REHERENCES}

1. J. B. Bal1, R. L. Auble, and F, G. Bore, Phys. Lattexe 298, 172 (1969).

2. A. Bohr, Int. Brup. on Buclear structure, Dubna, 1968。

3, B. Skrenoen, Kucl. Phye. A172, 465 (1971).

4. J. B. Ban1, R. In Aub2e, Jo Rapaport, and C. B, Lunar, Bhyo. Letere 308. $533(2969)$. 


\section{FIGURE CAPTIONS}

118. 1. Relative intensitieg for $0^{+}$states populated by $(p, t)$ reactions on 90,92 ze targets. The data shown 18 for an ineident protors energy of $38 \mathrm{MeV}$.

918. 2. Relative Intensities for $0^{+}$otates populated by $(p, t)$ reactions on $32,94 \mathrm{~kg}$ targets. The date shown 18 for an Ineddent proton energy of 31 MeV.

I8. 3. Relative Intengitier for $0^{+}$atates populated by on ${ }^{96} \mathrm{Ru}$. The dats abown 10 for an 1netdent. proter onergy of 31 rave 


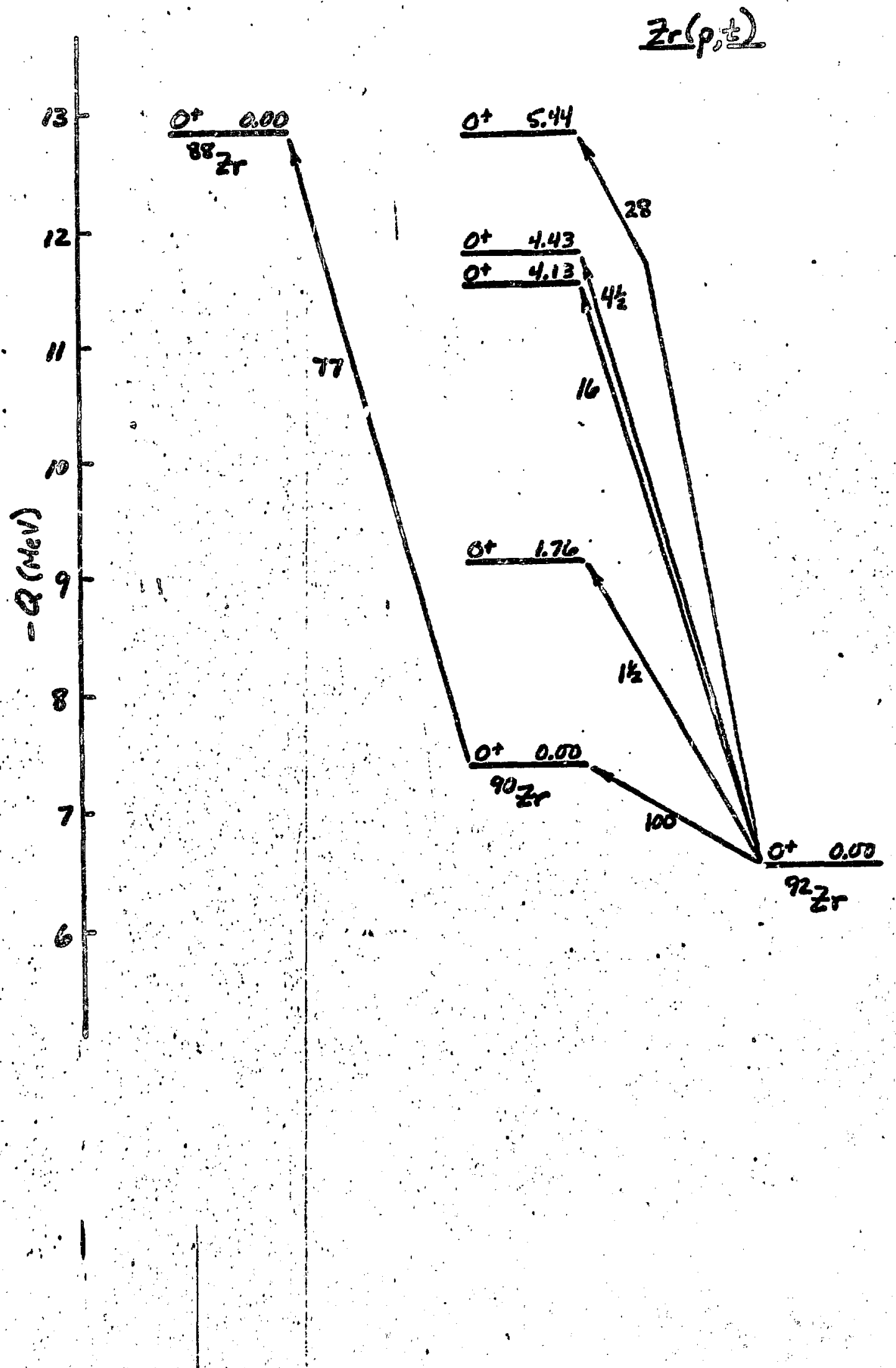


Mespot)
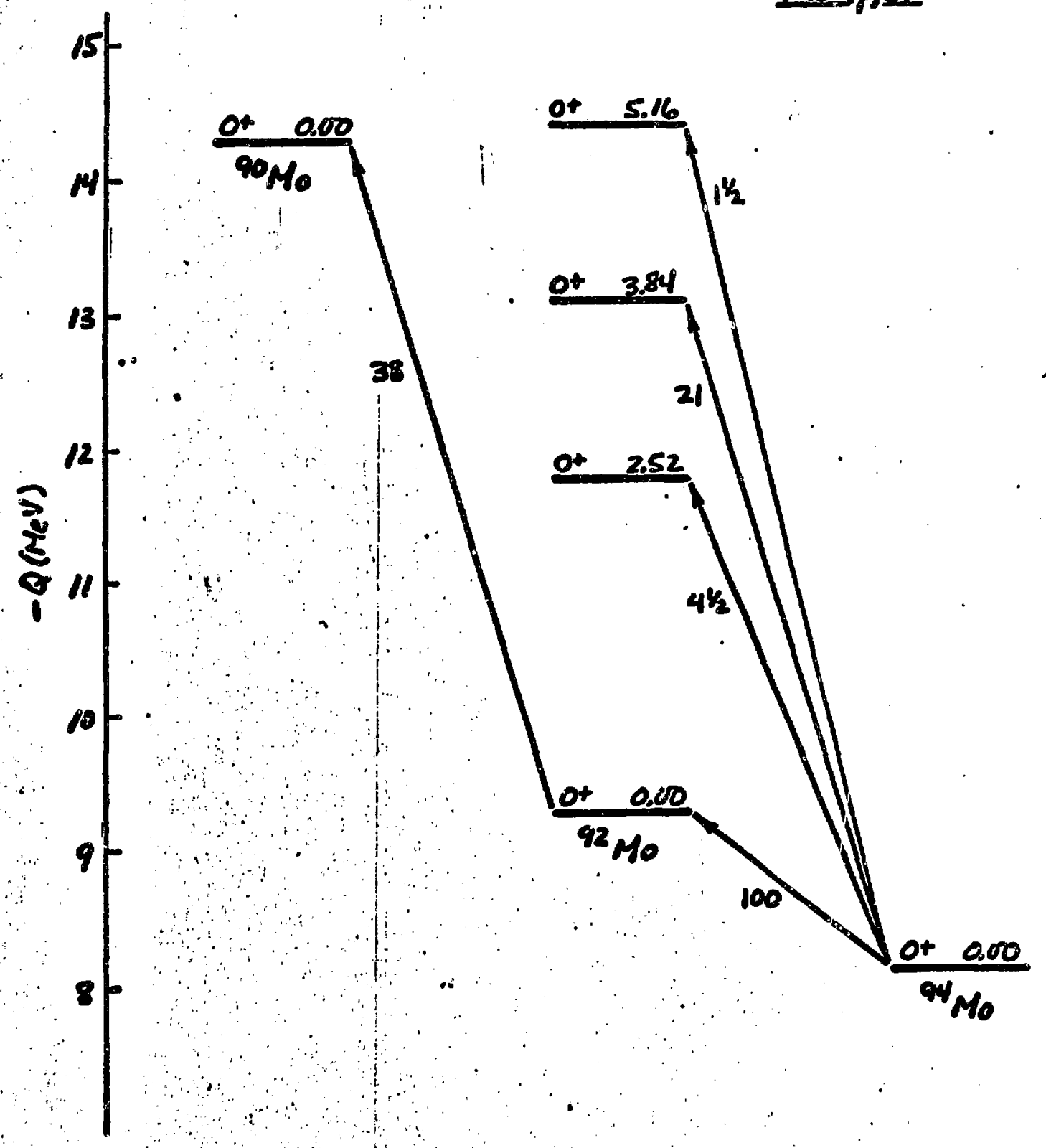


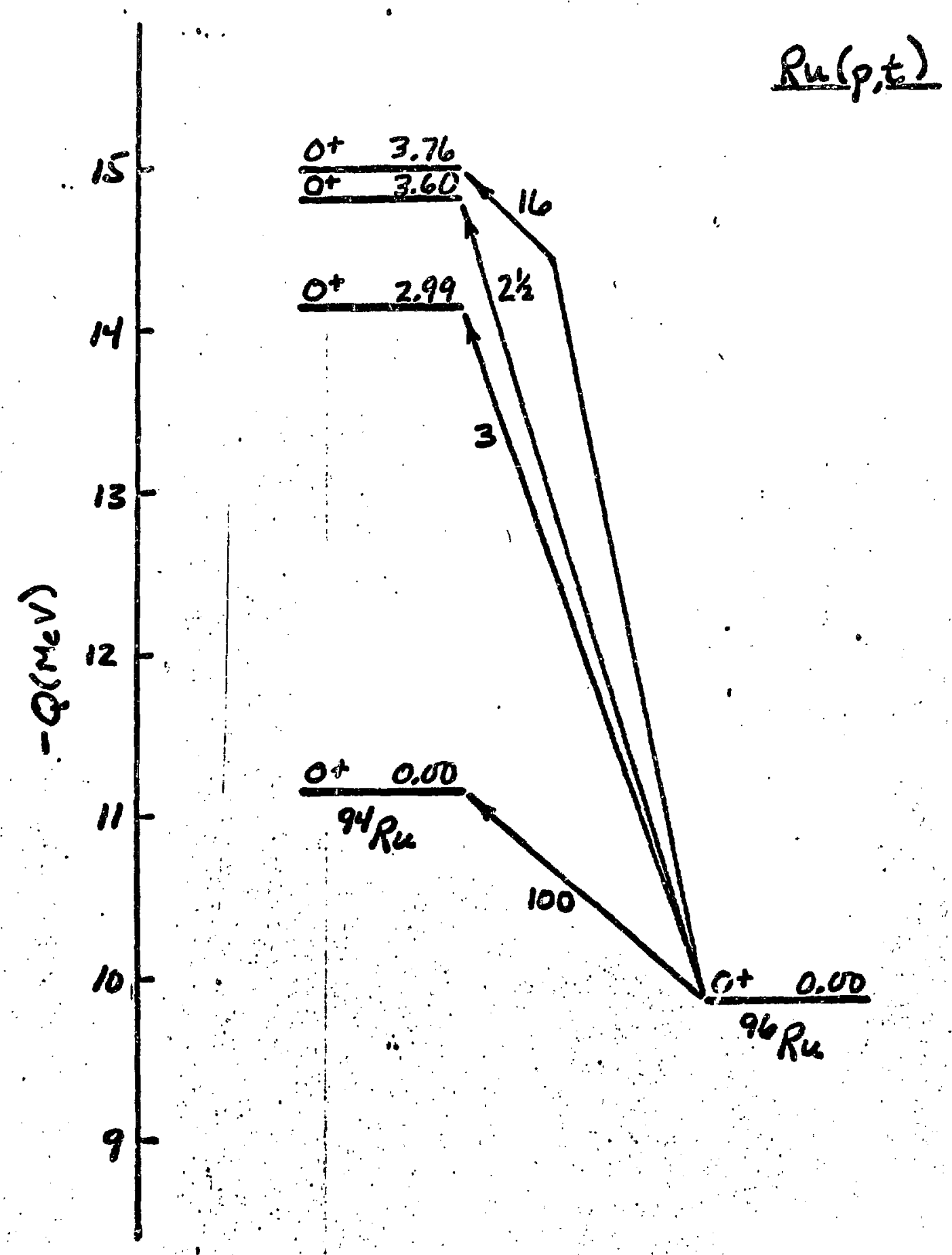

